\title{
STUDIES ON SOLUBLE CARBOHYDRATES IN YELLOW LUPIN (LUPINUS LUTEUS L.) SEEDS OF DIFFERENT AGE
}

\author{
KAZIMIERZ ZALEWSKI ${ }^{1}$, LESŁAW B. LAHUTA ${ }^{2}$ \\ ${ }^{1}$ Department of Biochemistry \\ 2 Department of Plant Physiology and Biotechnology, \\ University of Warmia and Mazury \\ Oczapowskiego 1A, 10-957 Olsztyn-Kortowo, Poland \\ e-mail:k.zalewski@uwm.edu.pl
}

(Received: August 28, 2006. Accepted: July 8, 2007)

\begin{abstract}
Yellow lupin seeds cv. Juno were stored under laboratory conditions for 2 month, 4,6 and 8 years. Eighteen soluble carbohydrates were identified in embryonic axes and cotyledons of different age seeds. The concentration of soluble carbohydrates in analysed seeds ranged from 25 to $34 \%$ of dry mass. Axes contained more carbohydrates than cotyledons. Stachyose dominated in axes, and verbascose - in cotyledons. Other detected galactosides were: galactinol, galactosyl pinitols and galactosyl chiro-inositols (fagopyritols), but their content was several-fold lower than that of RFOs (in both axes and cotyledons tissues). The concentration of soluble carbohydrates indicated, that sucrose to RFOs mass ratio, or other changes in sugars composition are not indicators of seed storage.
\end{abstract}

KEY WORDS: Lupinus luteus seeds, raffinose, cyclitols, ageing.

\section{INTRODUCTION}

Yellow lupine cv. Juno is the most popular cultivar of lupin growing in Poland. However, it is difficult to obtain high-quality seeds of this cultivar since Lupinus plants are often infested with fungi during the growing season (Frencel 1999). Thus, seed material characterized by high germination capacity is obtained once in several years, and should be stored and distributed among producers. Therefore, the lowering viability of yellow lupine seeds during storage is an important agricultural problem. Some experiments concerning the viability of yellow lupin seeds during storage suggest, that oligosaccharides accumulated during seed maturation can reflect the seed storability (Lahuta et al. 2000a; Piotrowicz-Cieślak 2005). The presence of raffinose and its higher homologue - stachyose in embryo tissue is directly related to protoplast stability during seed storage (Horbowicz and Obendorf 1994; Still et al. 1994; Crowe et al. 1996). It has been demonstrated, that some oligosaccharides with different degree of polymerization can promote transition of cellular contents to the vitreous (glassy) state that protects macromolecular structures and membranes at very low water concentration (Bernal-Lugo and Leopold 1995; Sun and Leopold 1997; Bryant et al. 2001; Hoekstra et al. 2001; Oliver et al. 2002; Hincha et al. 2003; Cacela and Hincha 2006). Unfavorable storage conditions (elevated air relative humidity and temperature) can induce hydrolysis of oligosaccharides and increase the rate of respiration, leading to some deteriorative changes, like lipid peroxidation or protein destruction (Murthy et al. 2000, 2003). Therefore stabilization of vitreous state and on the other hand prevention of sugars hydrolysis can be important factors promoting seed viability. In the present study we have investigated the composition of soluble carbohydrates in stored yellow lupin seeds to find the possible characteristic changes in carbohydrates associated with seed deterioration.

\section{MATERIAL AND METHODS}

The viability of the yellow lupin cv. Juno seeds after harvest and during 2 months, 4, 6 and 8 years of storage at laboratory conditions (at $18-20^{\circ} \mathrm{C}$ and mean humidity of 55 $-60 \%$ ) was determined using the method according to the ISTA rules (1996). Seed viability was measured as a percent of germinated seeds after imbibition over 14 days on the moistened germination paper (Anchor paper Company, St. Paul, USA) in darkness at $20^{\circ} \mathrm{C}$. Seed vigour was estimated after 3 or 4 days of germination and expressed as fresh and dry weight of roots (with hypocotyl).

\section{Assay of soluble carbohydrates}

Extraction and assay of soluble carbohydrates by gas chromatography method in embryonic axes and cotyledons were performed as described previously (Zalewski et al. 2001). 
TABLE 1. Germination and vigour of yellow lupin seeds after harvest and during storage.

\begin{tabular}{|c|c|c|c|c|}
\hline \multirow{3}{*}{$\begin{array}{c}\text { Year } \\
\text { of seeds harvest }\end{array}$} & \multicolumn{2}{|c|}{ Germination capacity } & \multicolumn{2}{|c|}{ Seed vigour } \\
\hline & \multicolumn{2}{|c|}{$(\%)$} & \multicolumn{2}{|c|}{$\mathrm{mg}(\text { root }+ \text { hypocotyl) })^{-1}$} \\
\hline & After harvested & During storage & Fresh weight & Dry weight \\
\hline 2003 & 92.0 & 92.0 & 11.675 & 0.823 \\
\hline 1999 & 96.5 & 65.5 & 10.243 & 0.912 \\
\hline 1995 & 68.0 & 6.5 & 3.198 & 0.465 \\
\hline LSD, $\mathrm{p}=0.01$ & 3.25 & 4.47 & 0.642 & 0.077 \\
\hline
\end{tabular}

\section{RESULTS}

Yellow lupin grown in Poland is more sensitive to the conditions prevailing at the final stage of seed formation and ripening than any other legume species. For instance, during the years 1994 and 1995 the germination capacity of yellow lupin seeds, cv. Juno, was $40 \%$ and $68 \%$ respectively. Therefore, the oldest seeds and seeds strongly infected with fungi were eliminated prior to analysis. The remaining seed lots (obtained during the years 1997 to 2003) were characterized by high viability, which decreased over the storage period (Table 1).

Analyses of soluble carbohydrates indicated, that the embryonic axes contained more carbohydrates than cotyledons (Fig. 1). Soluble carbohydrates were presented by raffinose family oligosaccharides (RFOs), sucrose and $\alpha$-Dgalactosides of D-pinitol (galactosyl pinitols) and $\alpha$-D-galactosides of D-chiro-inositol (fagopyritols). However, the concentration of galactosyl cyclitols was several-fold lower than that of RFOSs (Fig. 2 and 3). Among oligosaccharides presented in axes dominated stachyose and in cotyledons verbascose. This composition was characteristic for this lupin species and didn't change during seed storage. In both axes and cotyledons galactosyl cyclitols were di-galactosides - ciceritol (di-galactosyl D-pinitol A) and fagopyritol B2 (di-galactosyl D-chiro-inositol).

The concentration of sucrose in stored seeds was below $2 \% \mathrm{DW}$ and the concentrations other compounds, like galactinol, myo-inositol, D-pinitol and D-chiro-inositol appea-

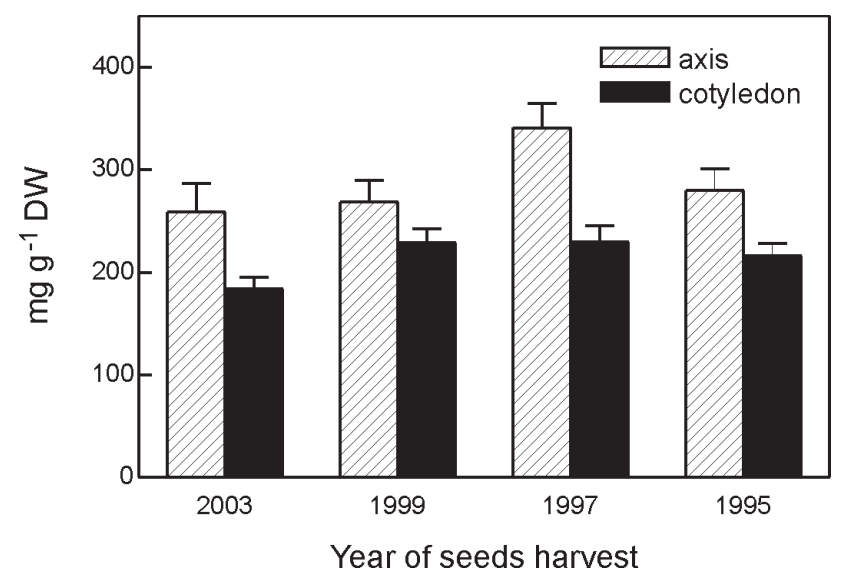

Fig. 1. The concentration of total soluble carbohydrates $\left(\mathrm{mg} \mathrm{g}^{-1}\right.$ dry weight, DW) in embryonic axes and cotyledon in yellow lupin seeds stored for 2 months, 4, 6 and 8 years (2003, 1999, 1997, and 1995, respectively). Mean of three replicates \pm SE. red at very low level (below $0.5 \% \mathrm{DW}$ ) (data not shown) or in traces (di-galactosyl myo-inositol). There are no cor-
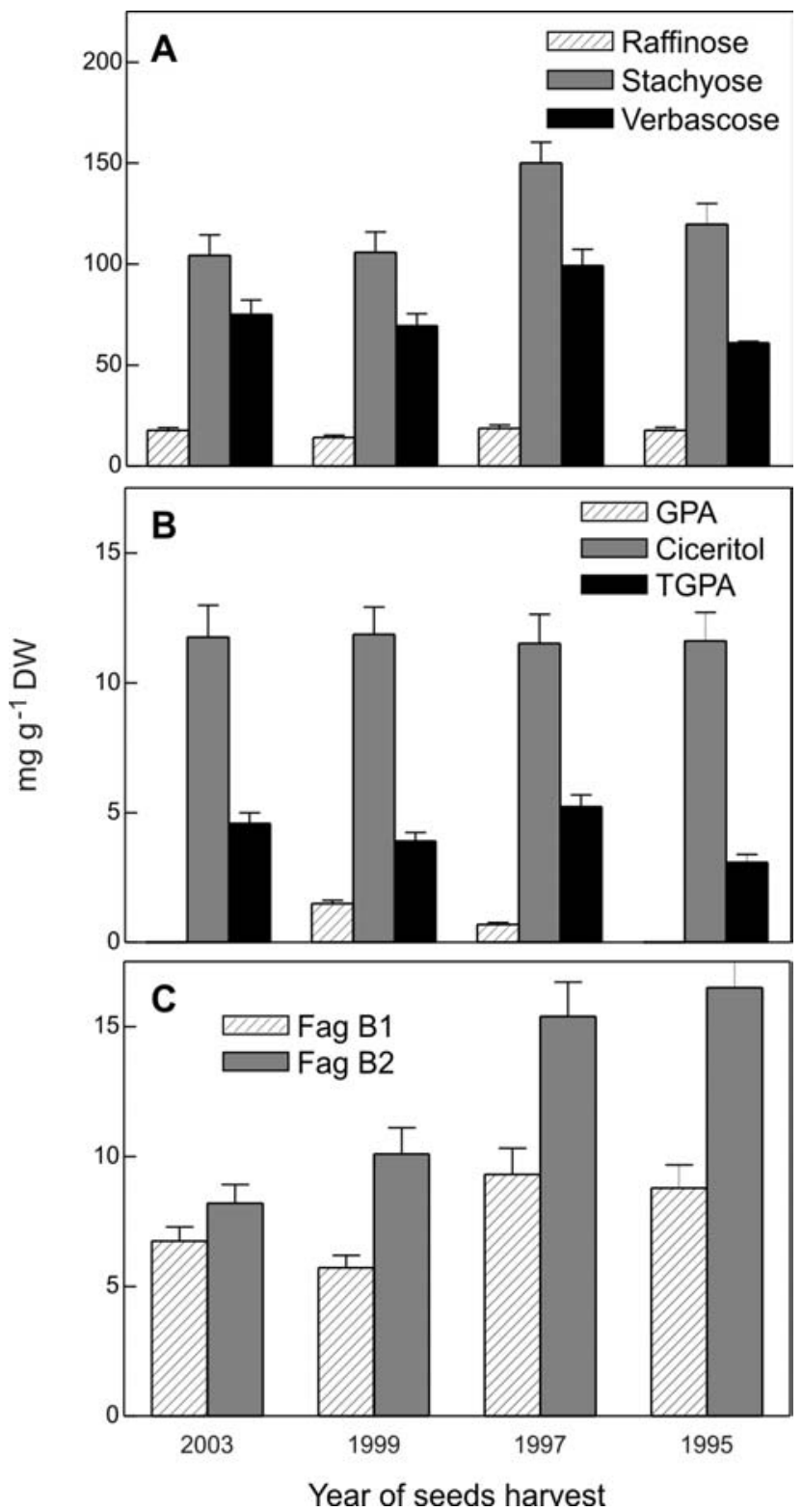

Fig. 2. The concentration of raffinose family oligosaccharides (A), $\alpha-D-$ galactosides of D-pinitol (B) and $\alpha$-D-galactosides of D-chiro-inositol (C) in embryonic axes of stored yellow lupin seeds. Abbreviations: GPA galactosyl pinitol A; ciceritol - di-galactosyl pinitol A; TGPA - tri-galactosyl pinitol A; Fag B1 - fagopyritol B1 (galactosyl D-chiro-inositol); Fag B2 - fagopyritol B2 (di-galactosyl D-chiro-inositol). Mean of three replicates $\pm \mathrm{SE}$. 

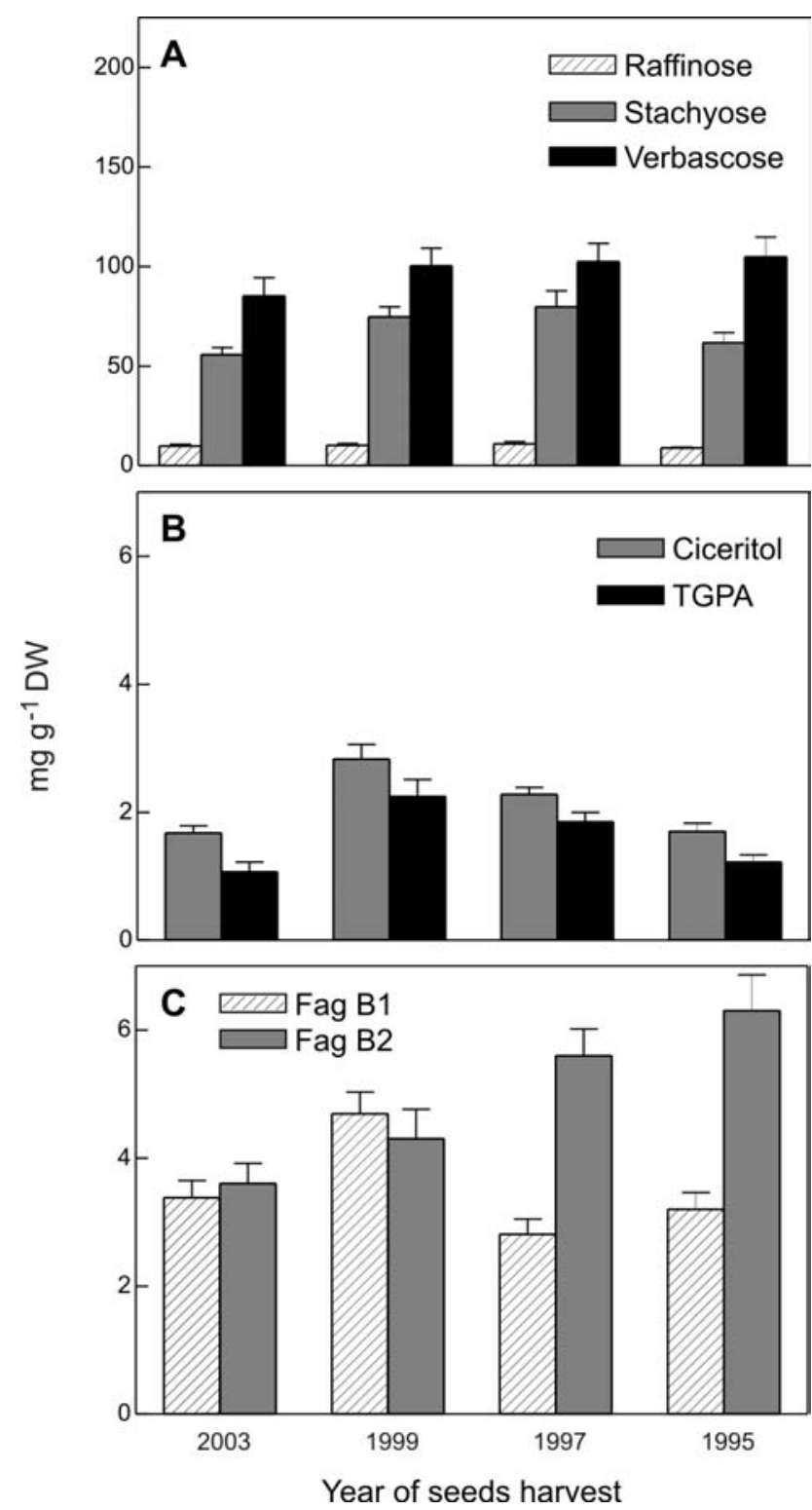

Fig. 3. The concentration of raffinose family oligosaccharides (A), $\alpha$-Dgalactosides of D-pinitol (B) and $\alpha$-D-galactosides of D-chiro-inositol (C) in embryonic cotyledons of stored yellow lupin seeds. Mean of three replicates \pm SE.

relations between sucrose to RFOSs mass ratio (for 2003, 1999, 1997 and 1995 it was: 0.06, 0.13, 0.06 and 0.1, respectively) and seed viability or seed vigour. Although seeds were stored for different periods they did not contain detectable contents of reducing sugars, or their derivatives.

\section{DISCUSSION}

Changes in the concentrations of phospholipids and carbohydrates protecting them decide about the rate of seed ageing under variable environmental conditions (Horbowicz and Obendorf 1994; Zalewski and Lahuta 1998). The decrease in seed viability observed over storage is also dependent on their chemical composition. A distinguishing feature of yellow lupine seeds is the high (35\%) content of carbohydrates, mostly hemicelluloses and oligosaccharides, and low amounts of starch and glucose.

According to Gojło et al. (2003), it is unlikely that there exists a direct correlation between the levels of raffinose family oligosaccharides (RFOs) and galactosyl cyclitols (GA-C) and seed resistance to unfavorable storage conditions (accelerated ageing). The common feature of ageing seeds of the genus Vicia is accumulation of sorbitol, most noticeable in rapidly ageing species, like $V$. sativa and $V$. villosa. It is interesting that the increase in sorbitol concentration takes place also in seeds unable to germinate. It remains unknown whether in this case sorbitol is formed on the basis of monosaccharides released from sucrose or from RFOs or other sources. Similar changes were observed at last in artificial aged pea seeds (Lahuta et al. 2007, in press).

Results of studies on Brassica campestris (Verma et al. 2003) showed that the levels of total soluble carbohydrates in seeds increased significantly with age, which was also observed in experiments on Brassica juncea (Verma et al. 1999). In the present study it was found that yellow lupin seeds contain considerable amounts of raffinose family oligosaccharides. These compounds perform many physiological functions in plants and improve the keeping quality of seeds. It is suggested, that the sucrose to oligosaccharides mass ratio can be an indicator of seed storage quality (Horbowicz and Obendorf 1994). Confirmation of this hypothesis was found by Piotrowicz (2005) in yellow lupin seeds stored for 10 years. However in our experiment not any correlation between sucrose to RFOs mass ratio and seed viability was found. Strong differences between the concentrations of soluble carbohydrates in stored lupin seeds can be rather the result of seed maturation conditions than seed storage. Unfavorable water conditions during seed development and maturation stimulate accumulation of higher amounts of oligosaccharides in field bean (Lahuta et al., 2000b) and yellow lupin (Zalewski et al. 2001) seeds.

It is believed that accumulation of reducing sugars leads to embryo deterioration according to increasing rate of seed respiration (Murthy et al. 2003). Therefore the formation of sorbitol can be a metabolic adjustment to reducing pool of monosaccharides. In accelerated Vicia (Gojło et al. 2003) and pea seeds (Lahuta et al. 2007) the accumulation of sorbitol increased linearly during seeds ageing. However sorbitol was not detected in naturally stored yellow lupin seeds. It may mean, that during dry seed storage, only discrete metabolic changes occur, and those changes can be observed only by elevating tissues' moisture and by higher temperature. Therefore, we suggest, that measurement of the carbohydrates level without analysis of enzyme activities in stored seeds are not sufficient to resolve the potentially involvement of sugars in seed storability.

\section{LITERATURE CITED}

BERNAL-LUGO I., LEOPOLD A.C. 1995. Seed stability during storage: Raffinose content and seed glassy state. Seed Sci. Res. 5: 75-80.

BRYANT G., KOSTER K.L., WOLFE J. 2001. Membrane behaviour in seeds and other systems at low water content: the various effects of solutes. Seed Sci. Res. 11: 17-25.

BUITINK J., HEMMINGA M.A., HOEKSTRA F.A. 2000. Is there a role for oligosaccharides in seed longevity? An assessment of intracellular glass stability. Plant Physiol. 122: 1217$-1224$.

CACELA C., HINCHA D.K. 2006. Monosaccharide composition, chain length and linkage type influence the interactions 
of oligosaccharides with dry phosphatidylcholine membranes. Biochim. Biophys. Acta 1758: 680-691.

CROWE J.H., HOEKSTRA F.A., NGUYEN K.H.N., CROWE L.M. 1996. Is vitrification involved in depression of the phase transition in dry phospholipids? Biochim. Biophys. Acta 1280: 187-196.

FRENCEL I. 1999. Progress in research on lupin anthracnose in Poland and Europe. International Conference "Lupin in Polish and European Agriculture. Przysiek, 2-3.IX.", pp. 199-207.

GOJŁO E., LAHUTA L.B., GÓRECKI R.J. 2003. The effect of accelerated ageing on Vicia seeds germination and soluble sugars composition. International Workshop on Applied Seed Biology "New Developments in Seed Quality Improvement. Łódź, Poland, 23-25.IX", pp. 74-75.

HINCHA D.K., ZUTHER E., HEYER A.G. 2003. The preservation of liposomes by raffinose family oligosaccharides during drying is mediated by effects on fusion and lipid phase transitions. Biochim. Biophys. Acta 1612: 172-177.

HOEKSTRA F.A., GOLOVINA E.A., BUITINK J. 2001. Mechanisms of plant desiccation tolerance. Trends Plant Sci. 6: 431-438.

HORBOWICZ M., OBENDORF R.L. 1994. Seed desiccation tolerance and storability. Dependence and flatulence - producing oligosaccharides and cyclitols - review and survey. Seed Sci. Res. 4: 385-405.

International Seed Testing Association. 1996. Seed Sci. Technol. 24, Supplement.

LAHUTA L.B., GÓRECKI R.J., MICHALCZYK D., PIOTROWICZ-CIEŚLAK A.I. 2000a. The $\alpha$-galactosidase activity in stored yellow lupine (Lupinus luteus L.) seeds. Electronic Journal of Polish Agricultural Universities, Agronomia Vol. 3 (1): $1-8$.

LAHUTA L.B., ŁOGIN A., REJOWSKI A., SOCHA A., ZALEWSKI K. 2000b. Influence of water deficit on the accumulation of sugars in developing field bean (Vicia faba var. minor) seeds. Seed Sci. Technol. 28: 93-100.

LAHUTA L.B., GÓRECKI R.J., ZALEWSKI K., HEDLEY C.L. 2007. Sorbitol accumulation during natural and accelerated ageing of pea (Pisum sativum L.) seeds. Acta Physiol. Plant. DOI: $10.1007 / \mathrm{s}$ 11738-007-0063-0.
LEOPOLD A.C., SUN W.Q., BERNAL-LUGO I. 1994. The glassy state in seeds: analysis and function. Seed Sci. Res. 3: 267-274.

MURTHY U.M.N., KUMAR P.P., SUN W.Q. 2003. Mechanisms of seed ageing under different storage conditions for Vigna radiata (L.) Wilczek: lipid peroxidation, sugar hydrolysis, Maillard reactions and their relationship to glass state transition. J. Exp. Bot. 54: 1057-1067.

MURTHY N.U.M., SUN W.Q. 2000. Protein modification by Amadori and Maillard reactions during seed storage: roles of sugar hydrolysis and lipid peroxidation. J. Exp. Bot. 51: 1221$-1228$.

OLIVER A.E., HINCHA D.K., CROWE J.H. 2002. Looking beyond sugars: the role of amphiphilic solutes in preventing adventitious reactions in anhydrobiotes at low water contents. Comp. Biochem. Physiol., Part A 131: 515-525.

PIOTROWICZ-CIEŚLAK A.I. 2005. Changes in soluble carbohydrates in yellow lupin seed under prolonged storage. Seed Sci. Technol. 33: 141-145.

STILL D.W., KOVACH D.A., BREDFORD K.J. 1994. Development of desiccation tolerance during embryogenesis in rice (Oryza sativa) and wild rice (Zizania palustris). Plant. Physiol. 104: 431-438

SUN W.Q., LEOPOLD A.C. 1997. Cytoplasmic vitrification and survival of anhydrobiotic organisms. Comp. Biochem. Physiol, 117A (3): 327-333.

VERMA S.S., VERMA U., TOMER R.P.S. 2003. Studies on seed quality parameters in deteriorating seeds in Brassica (Brassica campestris). Seed Sci. Technol. 31: 389-396.

VERMA S.S., TOMER R.P.S., VERMA U. 1999. Studies on seed quality parameters in rape seed (Brassica juncea) stored under ambient conditions. Indian J. Agricult. Sci. 69: 840-842.

ZALEWSKI, K., LAHUTA, L.B., HORBOWICZ, M. 2001. The effect of soil drought on the composition of carbohydrates in yellow lupin seeds and triticale kernels. Acta Physiol. Plant. 23: 73-78.

ZALEWSKI K., LAHUTA L.B. 1998. Metabolism of ageing seeds. Changes in the raffinose family oligosaccharides during storage of field bean (Vicia faba v. minor Harz). Acta Soc. Bot. Pol. 67 (2): 193-196. 